\title{
The Enemy Within
}

\section{AN OLD WAR MANUAL REVEALS HOW BEHAVIORS SABOTAGE MODERN FIRMS}

By Nathan Jaye, CFA

In 1944, the US Office of Strategic Services, a forerunner of the CIA, created the Simple Sabotage Field Manual, a classified booklet of tactics to help the European resistance movements destroy the Axis occupation forces from within. More than 70 years later, these same behaviors still lurk in our midst, causing dysfunction and inefficiency in the modern workplace. Cary Greene, a partner at the consulting firm Strategic Offsites Group, is co-author (with Robert Galford and Bob Frisch) of Simple Sabotage: A Modern Field Manual for Detecting and Rooting Out Everyday Behaviors That Undermine Your Workplace (September 2015). In an interview with CFA Institute Magazine, Greene discusses the ways that managers and employees can unintentionally sabotage their organizations and explains why reopening decisions may be one of an organization's worst enemies.
Sabotage tactics used in the Second World War can be found in presentday organizations but are caused by unintentional behaviors.

Cumulative effects of unintentional sabotage can damage organizations.

Preventing behavioral sabotage can improve performance, productivity, and decision making and build trust.

\section{What is the original Simple Sabotage Field Manual of 1944?}

The manual was originally a classified document published at the height of World War II by the OSS; it was declassified in the 1970s. The OSS manual provides a set of tactics for Allied supporters to sabotage institutions behind enemy lines, tactics to disrupt and demoralize the enemy's institutions without being detected. These were small, untraceable acts of sabotage designed to wear down the enemy over time and help the Allies win the war.
In particular, page 28 of the manual caught our attention. While most of the manual details physical acts of sabotage like slashing tires and draining fuel tanks, this page describes eight tactics for "General Interference with Organizations and Production." It includes tips for wasting time ("insist on doing everything through "channels" and "bring up irrelevant issues as frequently as possible") and how to bring efficiency to a halt ("refer all matters to committees"). Basically, it's a guide to sabotage the decision-making processes of an organization-very small acts that have large, damaging cumulative effects.

The manual intended the tactics to be done intentionally, but we found an ironic twist. We found that the eight tactics happen all the time in present-day organizations. But

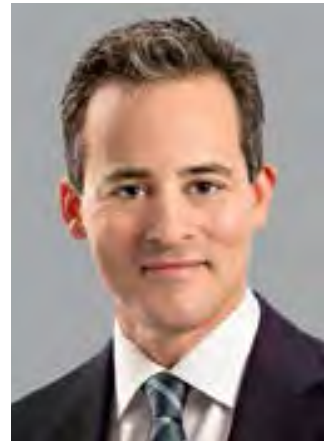

Cary Greene they're acts that are performed by people who are doing them unintentionally. They don't have a big plan to sabotage their organization, but the cumulative effect is just as damaging.

\section{What kind of organizations?}

Every organization is susceptible to these. We see them all the time in our work. Over a period of months, we showed page 28 of the Field Manual to hundreds of friends, colleagues, and clients. They all had the same reaction. They would laugh and say, "That list describes my [organization, department, volunteer group]." We heard them all.

These people were from big companies, small companies, for-profit and non-profit. That was our first revelation. The second thing was that there are ways to root out so-called sabotage and then do something about it. Hopefully, we can prevent it from happening again.

\section{What is "sabotage by obedience," as described in your book?}

In every organization, there is a set of rules, processes, and procedures. Some of them are formal; some, informal. They define the way in which you operate, and they are designed to be followed. Obedience is "playing by the book," which can be a good thing. However, we see cases where wellintentioned employees follow these rules to a fault.

For example, one of our clients relayed a story about a contract negotiation where the customer wanted a better price. To give them a better price, the employee would have had to get approval from his manager because the rule said you couldn't go below a certain price unless you've got a series of signoffs. The customer needed to make an immediate decision. But no one in the company was available for signoffs.

The employee didn't even consider violating the rule, even though he knew they could have easily recouped the costs in other ways. They ended up losing the business. The employee was obedient to a fault. The sabotage comes into play when a situation calls for good sound business judgment rather than just following a process.

We encourage clients to occasionally poll the employees. For example, "What's the stupidest rule or process we have around here?" It's amazing the responses you hear. Testing organizational procedures is really importanthaving people willing to revisit the rules they've put in 


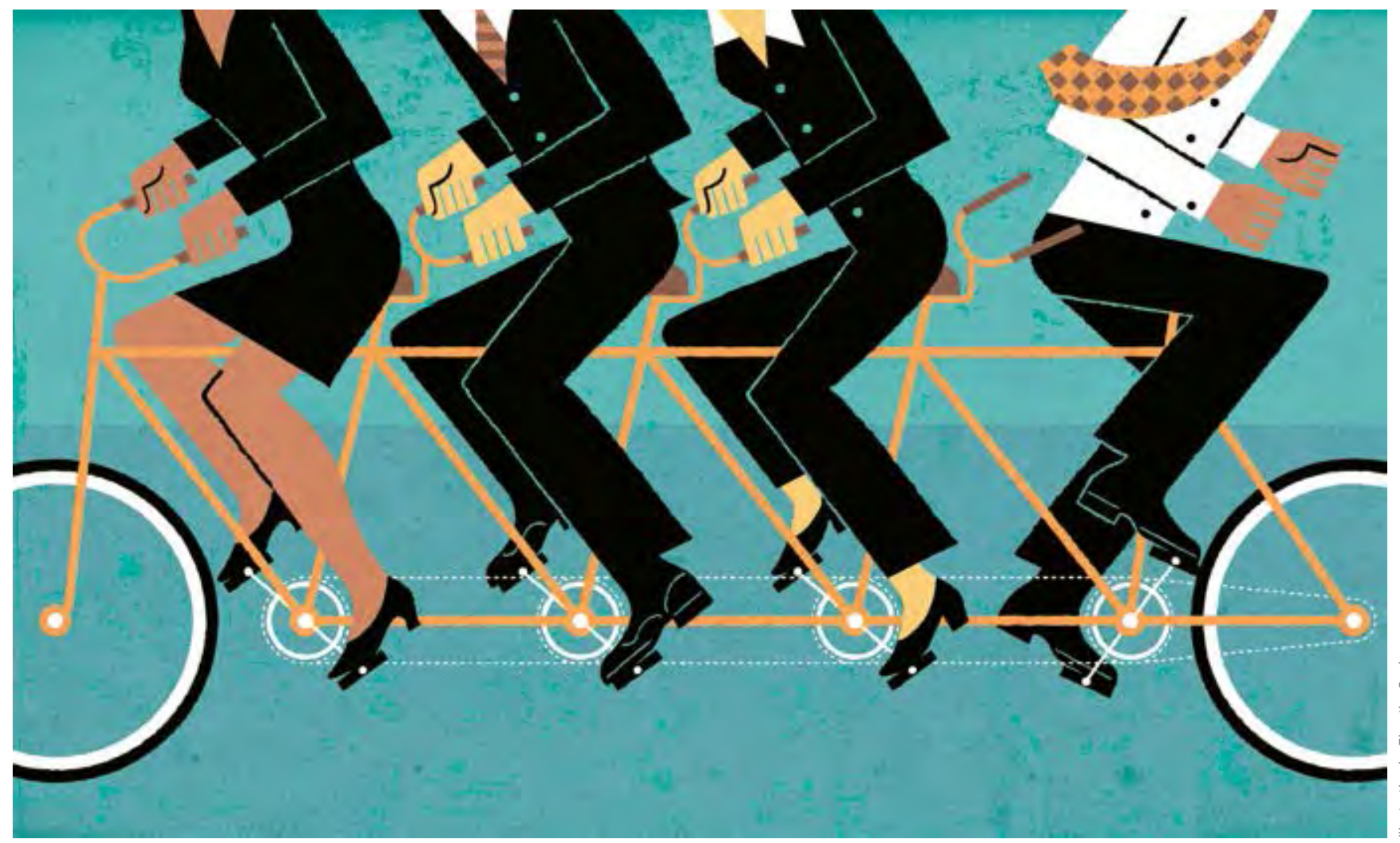

place-especially if people are following them to the detriment of the organization.

\section{Can an obedient saboteur be anyone? Can this person} be a manager, an outside consultant, or even an owner? Absolutely. And this goes for all of the sabotage tactics; it's not isolated to your line employee. In fact, it's fairly common to see well-intentioned saboteurs at the highest levels of the organization. CEOs, senior executives, or mid-level managers fall victim to these behaviors.

\section{How do you detect it?}

Obedient sabotage is a tough one to identify. But there are cases where you can spot it. An example would be if someone comes into a meeting and says, "Here's the situation. Based on our rules and procedures, I recommend this is what we do." Now, an astute person in the meeting may say, "That might be the way we've operated historically, but if we apply some further thinking, it probably makes sense to consider another route."

If you're able to spot it, you can actually do something about it. But it's not uncommon to find out after the fact that you lost a piece of business or a customer complained because a rule was followed.

\section{What's the right amount of rules for an organization?}

We talk about the concept of balance point. There's no standard formula for an organization, but the balance is between control and flexibility. On the one hand, there are rules, and on the other hand, there's flexibility and encouraging individuals to use their judgment to go outside of the rules as circumstances warrant. That varies for every organization.
For example, if I'm working in a manufacturing facility, I can only give people so much flexibility. There's a certain way of doing things. It's the same when it comes to safety or medical care or in other heavily regulated industries. But it's different for employees at a hotel front desk, for example. They might have the ability to upgrade a guest's room. Giving the folks at the front desk flexibility to make a decision makes a lot of sense.

\section{Who are speech saboteurs?}

Speech saboteurs are people (again, usually well intentioned) who talk frequently-typically using their personal experiences to make their point-but who are interjecting themselves in ways that are not particularly productive to the situation at hand.

We've all been in situations where we're having a timesensitive conversation. All of a sudden, a speech saboteur rears his head. These speech saboteurs come in a variety of packages. One is the "long talker." This is the person who just talks and talks and talks. A point that could be made in two minutes takes five minutes. There's never a quick yes or no answer. It's always, "Yes, and let me tell you why."

A second speech saboteur is called the "tangent talker." This is the individual who inevitably barrels off in a direction that is completely unrelated-or, at best, marginally related-to the topic at hand. Sometimes this behavior can be productive (for example, as an icebreaker). But if they're allowed to go on too long, they can significantly take away from your time and, in some cases, completely derail the conversation.

Another type of speech saboteur is the "lost talker." They start with the best intentions, but as they continue to talk, 
they lose track of the point. A clue to this particular saboteur is that after the person talks for a time, someone in the room says, "Would you mind summarizing what you said? We're not sure we're following you."

You also describe the "oh, oh talker" and the jargonista. As we were writing the book, I had a vision of Horshack from the 1970s television series Welcome Back, Kotter. Horshack always raises his hand in class and says, "Oh, oh, oh, Mr. Kotter? Mr. Kotter?" This is the person who practically falls over himself to make a point. At their best, these are people like Hermione Granger in the Harry Potter seriesthey know the topic inside and out. They are people who really cut to the chase.

But the "oh, oh talker" can also be a saboteur. These folks feel the need to contribute to every conversation. On every topic, they have something to say. Sometimes they just parrot back what they've heard before. They'll say, "I agree with Larry," and they'll just reiterate the same point Larry made. You end up in a spin cycle of a conversation. You just go around and around.

When the jargonista talks, he uses a lot of jargon, hence the name. In many cases, especially in investment banking and accounting and on Wall Street, there's a lot of jargon. It can be helpful to have someone provide a level of technical expertise. On the other hand, sometimes a person can't complete a sentence without using jargon instead of actual words. Inevitably, people start looking at each other and thinking, "I don't know what that means." One example is of a COO describing a product who said, "Succeeding with this product requires a soup-to-nuts approach." There were a lot of young, smart people in the room who had absolutely no idea what that phrase meant.

Another time, I was in a meeting where someone used the acronym NAGI. I was facilitating the conversation, and I stopped the meeting and said, "What does that mean?" It means, "not a good idea." Of course, a third of the room had never heard of it.

\section{How do you fix speech sabotage?}

One thing that's helpful, especially in a meeting or group conversation, is to establish what the conversation is designed to achieve. Make sure you have an allotted time to have the conversation and someone accountable for watching the clock. Also, think about who really needs to be there. There tends to be an inverse relationship between the number of people in a room and the ability to make a decision within a given period of time.

Establishing ground rules also helps. One of the ground rules we use in our meetings is called "jellyfish." If a speech saboteur emerges and we find ourselves on a tangent, anyone in the room can say, "This feels like a jellyfish moment."

The reason this works is that "jellyfish" is a safe word. It's established at the beginning of the meeting. No one needs to say, "Listen, I think we're off topic here. Sorry to cut you off, but we have to get back to the topic at hand." Anyone can say, "I think we're having a jellyfish moment. Let's park that for another time, because we have 15 minutes left and we have an important decision to make."

\section{What's the antidote to sabotage by committee?}

Here are three things to think about. When someone forms a committee, (1) make sure that there is a clear set of deliverables and the deadline is clear, (2) set a sunset date for when the committee should go out of existence, and (3) make the committee as small as possible. It's wise to avoid the suggestion of the 1944 Simple Sabotage Field Manual, which recommends making them as large as possible ("never less than five").

So the antidote (or part of the antidote) is to make committees small and focused. And make sure that your committee members are the right people; we do not usually advocate a volunteer approach.

\section{Who are hagglers?}

Hagglers are people who are continually debating or putting forward different viewpoints on how something should be written or said or how a key message should be conveyed. This can be a good thing when people are pushed to think further to consider more powerful words or ideas in communication. In some cases, hagglers can help an organization avoid potential embarrassment.

They become unintentional saboteurs when they're left unchecked and they draw people into an editing exercise with no clear end in sight, deflating an otherwise enthusiastic effort and making everyone frustrated, wasting time quibbling over every word (as the OSS hoped).

The "defender" is the most common and most passionate haggler. Their focus can be anything; it can be a word, a phrase, the overall message. They just can't resist the urge to demonstrate their value by marking up a document. It could be an email. It could be a press release, a client proposal, whatever. Often, they'll refuse to relinquish their point of view, even when it's clear the group doesn't agree and is ready to move on. Then it becomes sabotage.

Another type is the "grammar police." They go from one sentence to another, making suggestions usually related to grammar. They might say, "In the first sentence, you need a comma; in the second sentence, you are using a double negative." Undoubtedly, proper use of grammar is important. But these individuals will come into a room with a long list of edits - that is their singular focus.

The solution is to be thoughtful about how you solicit feedback. Often, people ask an open question along the lines of "What feedback do you have on this press release?" That is like throwing red meat to a pack of wolves. You are essentially opening yourself up to anything and everything. If you ask a more targeted and focused question ("Imagine 
you're a customer. What specific changes should we make to this email to increase the probability you will try our product?"), you will get much more valuable feedback.

\section{What's the danger in reopening decisions?}

Two of the most common sabotage techniques are sabotage by committee and then this one: sabotage by reopening decisions. We have all been in situations where a decision was made and then at some point someone tries to

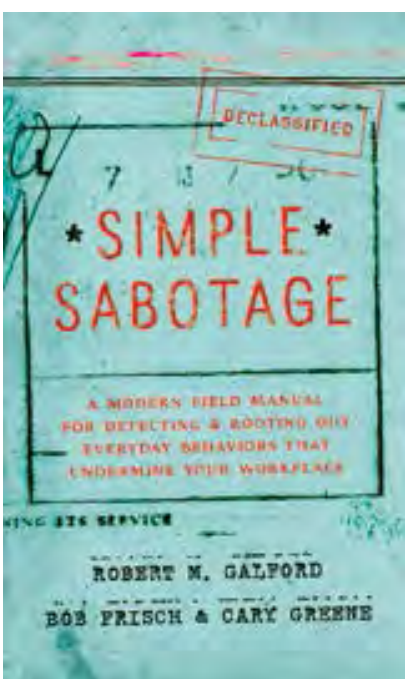
reopen the decision. It can be totally and completely irritating. When not legitimate, it's a total waste of time and creates tremendous resentment. There are cases where it's OK (especially in the investment arena) in situations where new data has only recently become available or when the circumstances surrounding the decision have changed in a meaningful way. Often, it comes down to why the decision is being reopened.

When it's sabotage, the saboteur (who didn't agree with the decision in the first place) may attempt to reopen the decision simply because it didn't go his way the first time. No new information is presented; circumstances have not changed. The individual just wants to make one more go at bringing people over to his side.

Another is, "I didn't tell you during the process, but I am telling you now: I think we should have made a different decision." The decision has been made, and she was part of the process, but she didn't say anything at the time.

\section{What's the effect on the organization?}

The consequences of reopening decisions without good reason — and doing it frequently—can be damaging and harmful to a business. If decisions are reopened frequently, people may become hesitant to make decisions at all. They'll fear that whatever they decide is going to be reopened anyway.

Organizations thrive on making decisions and making them stick. If you have a culture where decisions don't stick, that can significantly impact your organization's ability to pursue an opportunity, to move in a certain direction.

You have to weigh the cost-benefit of reopening a decision. Our general rule is, if there is no new and relevant information, then you should think twice about reopening a decision. In the investment arena, however, there is constantly new information appearing. So that might be a good reason, but you really have to make sure the reason is sound.

\section{You've added a ninth method of sabotage: sabotage by cc. Why?}

When the original manual was written, they didn't have email, so they weren't so worried about sabotage by cc. Today's data suggests that the average corporate email user sends and receives about 120 emails a day. Arguably, the more senior you are, the more email you receive. The amount of times that people are cc'd on emails as a percentage of that total is not insignificant.

More often than not, people are trying to cover for themselves. They may think, "If there is a doubt in anyone's mind that I didn't inform them about the email I'm about to send, I'm going to make sure they're copied. No one can say I didn't alert them." From our standpoint, that's sabotage. While unintentional, the frequency with which this occurs is quite high. People don't even think about copying five or ten people in an email. Cc'ing isn't a substitute for effective communication. When not necessary, it is another form of sabotage, shifting the burden to the receiver and taking the sender off the hook.

\section{What can be done? Isn't cc'ing a part of life?}

One thing is be proactive about unsubscribing from as many internal lists as possible. If you don't need it or you don't want it, be proactive about removing yourself from the list. The second thing is to be proactive about telling the individual who copies you to inform you personally rather than in an email. In terms of sending email, ask yourself, "Who really needs to know what I'm about to send, and is this the right means of communication?"

Email is not a substitute for personal dialogue. Be thoughtful about what's the appropriate form of communication. Is it email or perhaps walking down the hall or into the next office to communicate? Or maybe I should pick up the phone and have a conversation? Those are often great substitutes for just copying someone on an email they may never read.

\section{What's your vision for a nonsabotaged organization?}

We want to give people a language to recognize these unintentional behaviors that can do significant damage to an organization's productivity. Our goal in writing Simple Sabotage is to raise visibility, to give people a way to acknowledge and talk about these things, and (ultimately) to help organizations overcome sabotage in their cultures.

Our hope is that people will start to call out these sabotage tactics as they occur or even prevent the sabotage from happening in the first place. Doing so will make organizationsbig and small-more productive and more effective in their decision making and help build a greater level of trust as people have the vocabulary, the authority, and the tools to reduce sabotage and ultimately take the organization to another level of performance.

"Blame, Accountability, and Performance," CFA Institute Magazine (September/October 2014) [www.cfapubs.org]

"Sludge: Is a toxic culture poisoning your firm?" CFA Institute Magazine (May/June 2011) [www.cfapubs.org]
Nathan Jaye, CFA, is a speaker on intelligence and member of CFA Society San Francisco. 